\title{
Effect of statins on coronary bifurcation atherosclerosis: an intravascular ultrasound virtual histology study
}

\author{
Eun-Seok Shin • Hector M. Garcia-Garcia • \\ Takayuki Okamura • Patrick W. Serruys
}

Received: 17 August 2010/ Accepted: 28 November 2011

(C) Springer Science+Business Media, B.V. 2011

\begin{abstract}
This study is aimed at assessing by intravascular ultrasound virtual histology (VH-IVUS) the effect of statins on coronary bifurcation atherosclerosis in non-culprit vessels. In this non-randomized study, in 48 patients, 51 bifurcation atherosclerotic sites in nonculprit vessels without significant angiographic stenosis, underwent baseline and 12 months follow-up VHIVUS. Patients received treatment with either simvastatin $(20 \mathrm{mg}$ daily, $\mathrm{n}=24)$ or rosuvastatin $(10 \mathrm{mg}$ daily, $\mathrm{n}=24$ ) for the same period. VH-IVUS analysis of bifurcation lesions included the 5-mm proximal, bifurcation only (side-branch point) and 5-mm distal subsegments. Overall plaque and external elastic membrane volume decreased after 1 year $(115.7 \pm$ 35.5 to $106.1 \pm 29.3 \mathrm{~mm}^{3}, P<0.001$; and $241.0 \pm$ 57.0 to $232.4 \pm 54.2 \mathrm{~mm}^{3}, P=0.005$, respectively). Similarly, overall dense calcium volume significantly increased $\left(7.1 \pm 5.3\right.$ to $\left.11.0 \pm 8.5 \mathrm{~mm}^{3}, P<0.010\right)$, while fibrous and fibrofatty volumes significantly decreased $\left(36.9 \pm 19.2\right.$ to $24.1 \pm 11.7 \mathrm{~mm}^{3}, P<$ 0.001 ; and $5.1 \pm 3.8$ to $2.3 \pm 2.0 \mathrm{~mm}^{3}, P<0.001$, respectively), and necrotic core volume did not
\end{abstract}

E.-S. Shin · H. M. Garcia-Garcia - T. Okamura .

P. W. Serruys

Thoraxcenter, Erasmus MC, Rotterdam, The Netherlands

E.-S. Shin $(\bowtie)$

Department of Cardiology, Ulsan University Hospital, University of Ulsan College of Medicine, 290-3

Jeonha-dong, Dong-gu, Ulsan 682-714, South Korea

e-mail: ses@uuh.ulsan.kr change significantly $\left(17.0 \pm 11.1\right.$ to $19.8 \pm 13.5 \mathrm{~mm}^{3}$, $P=0.053)$. There were no significant differences in compositional analysis between the simvastatin and rosuvastatin treatment groups. However, within groups, necrotic core volume significantly increased in the simvastatin treatment group $(19.7 \pm 13.9$ to $\left.24.3 \pm 16.1 \mathrm{~mm}^{3}, P=0.029\right)$ but not in the rosuvastatin treatment group. $\left(14.3 \pm 6.7\right.$ to $15.6 \pm 8.7 \mathrm{~mm}^{3}$, $P=0.423)$. The independent clinical predictors for reduction of necrotic core volume by multiple stepwise logistic regression analysis were the percent change of HDL-cholesterol level $(P=0.041$, odds ratio: 1.052 , 95\% confidence interval (CI): 1.002 to 1.104$)$ and the percent change of hsCRP level $(P=0.021$, odds ratio: $0.989,95 \%$ CI: 0.980 to 0.998$)$. After 1 year, overall dense calcium volume significantly increased whilst fibrous and fibrofatty volumes significantly decreased; no significant change in the content of necrotic core was observed. Although changes in the volumes of all plaque components were not significantly different between the simvastatin and rosuvastatin treatment groups, halting of necrotic core progression was apparent in the rosuvastatin group.

Keywords Coronary bifurcation - Atherosclerosis . Statin · Plaque composition · Intravascular ultrasound

\section{Introduction}

Bifurcation sites are prone to develop atherosclerosis, as well as necrotic core-rich plaques [1-3]. As 
compared to other lesion subsets, percutaneous coronary intervention for bifurcation lesions is associated with a lower rate of procedural success and a higher rate of restenosis compared with that of non-bifurcation lesions [4-6]. Whether underlying plaque composition plays a role in this difference remains unknown.

Statin therapy improves long-term clinical outcomes in patients with coronary artery disease, and an intravascular ultrasound (IVUS) study has demonstrated the benefits of statin therapy on regression of coronary plaque size [7-9]. However, the effect of statin treatment on plaque composition in bifurcation lesions yet has not been evaluated. Intravascular ultrasound virtual histology (VH-IVUS), which permits the analysis of coronary plaque composition in vivo with high predictive accuracy, is increasingly used in clinical research [10-13]. Therefore, the aim of this study is to assess the effects of 1 year of treatment with statins on coronary bifurcation atherosclerosis of non-culprit vessels by VH-IVUS.

\section{Methods}

Study population

This study was conducted in one Korean center and included 48 consecutive patients with VH-IVUS assessment who had undergone successful elective coronary artery stenting with intermediate atherosclerosis in a non-culprit vessel. Enrollment period spanned from June 2005 to May 2006. These patients were randomly treated with simvastatin (20 mg daily) or rosuvastatin (10 mg daily) for a period of 1 year. Forty-eight patients with 51 de novo non-culprit bifurcation atherosclerotic sites without significant stenosis by coronary angiogram (diameter stenosis $<50 \%$ ) were included in the study. Only one site, namely the most proximal bifurcation site $(>1.5 \mathrm{~mm}$ side-branch ostium diameter) was selected from one major coronary vessel. All patients underwent baseline and 12-month VH-IVUS imaging. The exclusion criteria were hemodynamically unstable patients, cardiogenic shock, left main bifurcation and previous history of administration of lipid-lowering agents including statins. During the 1-year follow-up, the occurrence of major adverse cardiac events including death of any causes, acute myocardial infarction (elevation of the creatine kinase-myocardial band fraction to a value 3 times the upper limit of normal), and target-lesion revascularization (percutaneous or surgical intervention of these nonstenotic bifurcation lesions) was recorded. This study was performed with the patient's written informed consent and approval of the institutional review board.

VH-IVUS examination and analysis

Baseline and 1-year follow-up VH-IVUS examinations were performed before any intervention and after intracoronary administration of $200 \mu \mathrm{g}$ nitroglycerin with a motorized transducer pullback system $(0.5 \mathrm{~mm} / \mathrm{s})$. The 2.9-F IVUS imaging catheter (Eagle Eye, Volcano Corp., Rancho Cordova, California) incorporated a 20-MHz phased-array transducer. Off line analyses were done with personal computer VH program software (Volcano Therapeutics, Rancho Cordova, California) by an examiner who was unaware of the clinical characteristics of the subjects. We analyzed geometric and compositional characteristics of the $5 \mathrm{~mm}$-proximal, bifurcation only and $5 \mathrm{~mm}$-distal subsegments at the bifurcation sites (Fig. 1) Geometric quantitative IVUS analyses were performed according to criteria of the clinical expert consensus document on IVUS. External elastic membrane (EEM), lumen, and plaque \& media (P\&M) (P\&M = EEM-lumen) areas were obtained [14]. Plaque burden was defined as $\mathrm{P} \& \mathrm{M}$ divided by EEM area $\times 100$.

Compositional tissue characteristics were expressed in colors, as previously described (green for fibrous, yellow-green for fibrofatty, white for dense calcium, and red for necrotic core area) [15]. The VHIVUS analyses were reported in volumes and as percentages of volume. Percent change $(\%)$ of all variables was calculated as follows: ([follow-up value - baseline value]/[baseline value] $\times 100$ ).

\section{Statistical analysis}

All analyses were done using SPSS (version 16.0; SPSS Inc, Chicago, Illinois). Data are presented as frequencies or mean $\pm 1 \mathrm{SD}$. Comparison was performed with Chi-square statistics or Fisher exact test and paired or unpaired Student $t$ test or MannWhitney $U$ test accordingly. Nonparametric analysis with Wilcoxon signed rank test was also done. All patients were categorized as NC progressors (i.e., 

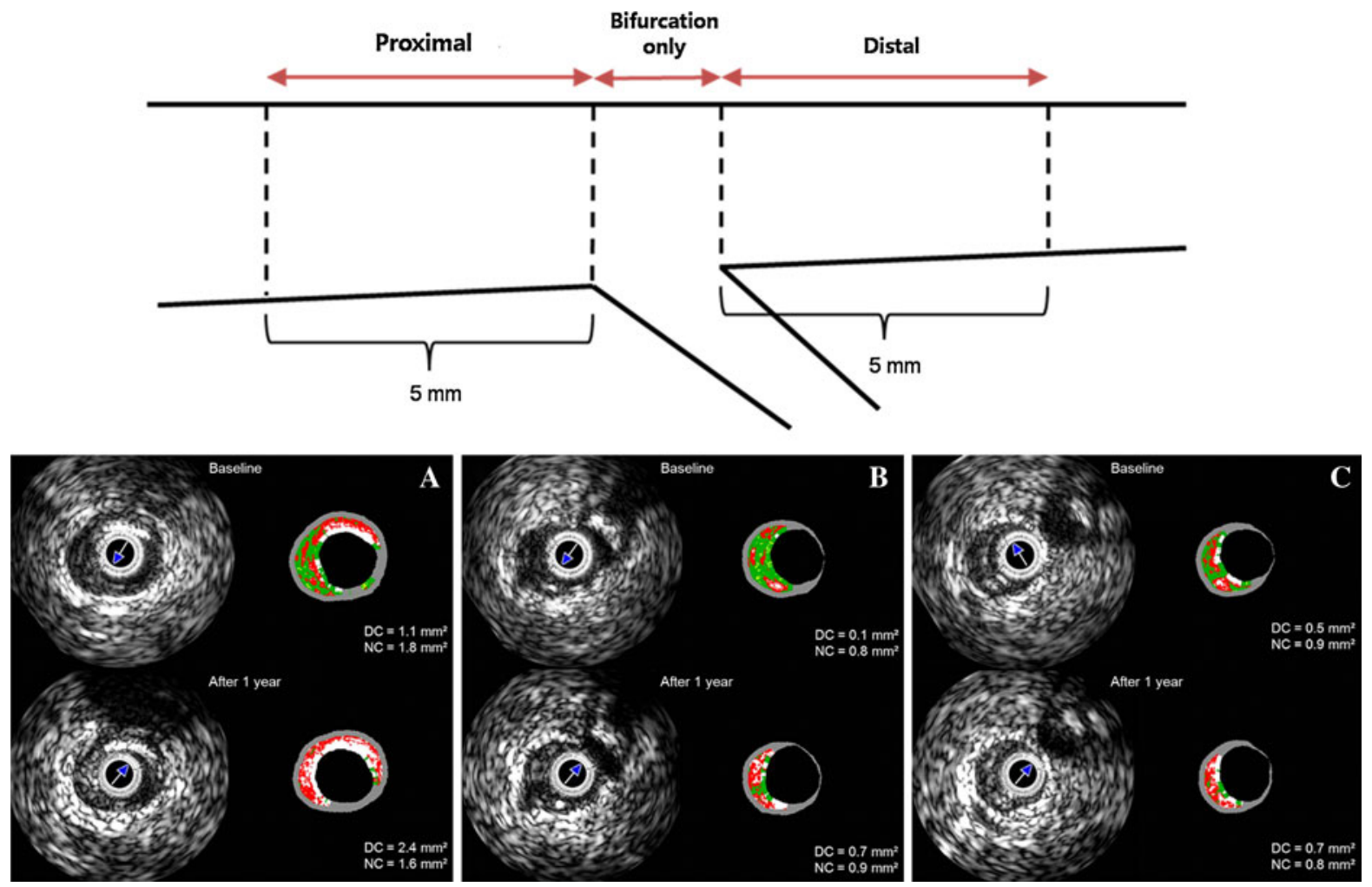

Fig. 1 Schematic definition of proximal, bifurcation only and distal subsegments for bifurcation sites. The proximal and distal subsegments of the bifurcation site were analyzed in the 5-mm proximal and distal to the bifurcation sites. The bifurcation-only segments were analyzed in each subsegment length. After 1 year, all subsegments show increased dense calcium by Virtual Histology intravascular ultrasound (a proximal; b bifurcation only; and c distal subsegments) patients with an increase in necrotic core volume after 1 year) and NC regressors (i.e., patients who had a decrease in necrotic core volume). Logistic regression analysis was performed to assess independent clinical predictors of decrease in necrotic core volume at 1 year. Statistical significance was accepted as $P$ less than 0.05 .

\section{Results}

Table 1 shows the baseline and clinical characteristics of the patients. Mean age of study participants was $61.3 \pm 8.5$ years, and there were 29 male subjects (60\%). The studied bifurcation site was the left anterior descending artery and diagonal branch in 27 patients $(56.3 \%)$, the left circumflex artery and obtuse marginal branch in $8(16.6 \%)$ and the right coronary artery and acute marginal branch in 13 (27.1\%). Table 1 shows not significant differences at baseline clinical characteristics between simvastatin and rosuvastatin treatment groups.

There were no significant differences at baseline and 12 months follow-up in high density lipoprotein (HDL)-, low density lipoprotein (LDL)-cholesterol and high sensitivity C-reactive protein (hsCRP) levels between the simvastatin and rosuvastatin treatment groups (Table 2). However, compared with the simvastatin treatment group, percent change of hsCRP level was significantly larger in the rosuvastatin treatment group $(11.1 \pm 116.1$ vs. $-53.5 \pm 41.3 \mathrm{mg} /$ $1, P=0.016)$. No major adverse cardiac events occurred during the 12-month follow-up period.

Serial changes of geometric and compositional variables in all patients

Geometric and compositional analyses are shown in Table 3. Overall, there were significant changes in geometric IVUS plaque volumes: EEM volume 
Table 1 Baseline clinical characteristics between simvastatin and rosuvastatin treatment groups
Values are presented as number (\%) or mean $\pm \mathrm{SD}$

ACS acute coronary syndrome, $P C I$ percutaneous coronary intervention, $C A B G$ coronary artery bypass grafting, $C A D$ coronary artery disease, $A C E$ angiotensin converting enzyme, $L A D$ left anterior descending artery, $L C X$ left circumflex artery, $O M$ obtuse marginal artery, $A M$ acute marginal artery

\begin{tabular}{|c|c|c|c|}
\hline & Simvastatin $(n=24)$ & Rosuvastatin $(\mathrm{n}=24)$ & $P$ \\
\hline Age (years) & $60.2 \pm 8.2$ & $61.6 \pm 9.3$ & 0.45 \\
\hline Male & $16(72.7)$ & $13(56.5)$ & 0.21 \\
\hline Body mass index $\left(\mathrm{kg} / \mathrm{m}^{2}\right)$ & $25.4 \pm 2.6$ & $25.2 \pm 3.77$ & 0.82 \\
\hline \multicolumn{4}{|l|}{ History } \\
\hline Previous ACS & 0 & 0 & \\
\hline Previous PCI & 0 & 0 & \\
\hline Previous CABG (\%) & $1(4.2)$ & 0 & 0.24 \\
\hline \multicolumn{4}{|l|}{ Risk factors } \\
\hline Hypertension & $13(56.5)$ & $16(64.0)$ & 0.41 \\
\hline Hypercholesterolemia & $7(30.4)$ & $10(40.0)$ & 0.35 \\
\hline Diabetes mellitus & $6(26.1)$ & $7(28.0)$ & 0.57 \\
\hline Current smoking & $7(30.4)$ & $7(28.0)$ & 0.55 \\
\hline Family history of CAD & $1(4.3)$ & $1(4.0)$ & 0.73 \\
\hline \multicolumn{4}{|l|}{ Medication (\%) } \\
\hline Aspirin & $24(100)$ & $24(100)$ & \\
\hline ACE inhibitor & $4(17)$ & $7(29)$ & 0.50 \\
\hline Beta blocker & $19(79)$ & $22(92)$ & 0.50 \\
\hline Calcium antagonist & $20(83)$ & $19(79)$ & 0.74 \\
\hline Clopidogrel & $23(96)$ & $24(100)$ & 0.49 \\
\hline Clinical presentation & & & 0.27 \\
\hline Stable angina & $9(38)$ & $13(54)$ & 0.40 \\
\hline ACS & $14(58)$ & $12(50)$ & 0.40 \\
\hline \multicolumn{4}{|l|}{ Bifurcation site } \\
\hline LAD and diagonal & $11(47.8)$ & $16(64.0)$ & 0.46 \\
\hline LCX and OM & $4(17.4)$ & $4(16.0)$ & 0.46 \\
\hline $\mathrm{RCA}$ and $\mathrm{AM}$ & $8(34.8)$ & $5(20.0)$ & 0.22 \\
\hline Follow-up period (day) & $359 \pm 37$ & $361 \pm 19$ & 0.80 \\
\hline
\end{tabular}

$\left(241.0 \pm 57.0\right.$ to $\left.232.4 \pm 54.2 \mathrm{~mm}^{3}, \quad P=0.005\right)$, $\mathrm{P} \& \mathrm{M}$ volume $\left(115.7 \pm 35.5\right.$ to $106.1 \pm 29.3 \mathrm{~mm}^{3}$, $P<0.001)$. The VH-IVUS analysis showed that dense calcium volume significantly increased $(7.1 \pm 5.3$ to $11.0 \pm 8.5 \mathrm{~mm}^{3}, P<0.001$ ), while fibrous and fibrofatty plaque volumes significantly decreased $\left(36.9 \pm 19.2\right.$ to $24.1 \pm 11.7 \mathrm{~mm}^{3}, P<0.001$; and $5.1 \pm 3.8$ to $2.3 \pm 2.0 \mathrm{~mm}^{3}, P<0.001$, respectively) after statin treatment for a period of 1 year. Although necrotic core percentage increased after 1 year, the volume change did not achieve statistical significance $\left(17.0 \pm 11.1\right.$ to $\left.19.8 \pm 13.5 \mathrm{~mm}^{3}, P=0.053\right)$.

Differential effect of statins on geometric and compositional variables

In both statin groups, there were significant changes in plaque volumes from baseline to follow-up $\left(125.3 \pm 44.0\right.$ to $113.5 \pm 33.5 \mathrm{~mm}^{3}, P=0.018$ in the simvastatin treatment group; and $106.5 \pm 22.0$ to $98.9 \pm 23.0 \mathrm{~mm}^{3}, P=0.001$ in the rosuvastatin treatment group) (Table 4). In both groups, there was a significant increase in dense calcium volume $\left(7.8 \pm 5.8\right.$ to $13.6 \pm 10.5 \mathrm{~mm}^{3}, P<0.001$ in the simvastatin treatment group; and $6.4 \pm 4.9$ to $8.5 \pm 4.8 \mathrm{~mm}^{3}, P=0.008$ in the rosuvastatin treatment group), while fibrous and fibrofatty volumes significantly decreased $(41.1 \pm 23.6$ to $23.8 \pm$ $12.2 \mathrm{~mm}^{3}, \quad P<0.001$, and $5.7 \pm 4.3$ to $2.1 \pm$ $2.2 \mathrm{~mm}^{3}, P=0.001$, respectively, in the simvastatin treatment group; and $33.0 \pm 13.0$ to $24.2 \pm$ $11.4 \mathrm{~mm}^{3}, \quad P<0.001$, and $4.6 \pm 3.3$ to $2.4 \pm$ $1.8 \mathrm{~mm}^{3}, P=0.001$, respectively, in the rosuvastatin treatment group). While necrotic core volume increased in the simvastatin treatment group (19.7 \pm $13.9 \mathrm{~mm}^{3}$ to $\left.24.3 \pm 16.1 \mathrm{~mm}^{3}, P=0.029\right)$ and in 
Table 2 Laboratory results

Values are presented mean $\pm \mathrm{SD}$

$H D L-C$ high-density lipoprotein cholesterol, $L D L-C$ low-density lipoprotein cholesterol, hsCRP high sensitivity C-reactive protein ${ }^{*} P=0.48 ;{ }^{*} P=0.013$

Table 3 Changes in geometric and compositional characteristics at bifurcation sites
Values are presented mean $\pm \mathrm{SD}$

EEM external elastic membrane, $P \& M$ plaque and media, $D C$ dense calcium, $F I$ fibrous, $F F$ fibrofatty, $N C$ necrotic core

\begin{tabular}{llllr}
\hline & Baseline & Follow-up & Percent change (\%) & \multicolumn{1}{c}{$P$} \\
\hline Body mass index & $25.5 \pm 3.5$ & $25.3 \pm 3.2$ & $-0.6 \pm 6.0$ & 0.406 \\
Total cholesterol (mg/dl) & $181.0 \pm 46.4$ & $133.5 \pm 26.3$ & $-23.2 \pm 19.3$ & $<0.001$ \\
Triglyceride (mg/dl) & $187.9 \pm 154.5$ & $121.4 \pm 66.4$ & $-21.3 \pm 36.3$ & 0.004 \\
HDL-Cholesterol (mg/dl) & $47.1 \pm 18.0$ & $52.2 \pm 12.9$ & $16.2 \pm 24.9$ & 0.032 \\
Simvastatin & $45.6 \pm 11.7$ & $51.5 \pm 13.2$ & $14.5 \pm 19.5$ & 0.004 \\
Rosuvastatin & $48.5 \pm 22.8$ & $53.0 \pm 12.8$ & $17.9 \pm 29.7$ & 0.051 \\
LDL-cholesterol (mg/dl) & $100.0 \pm 41.5$ & $57.0 \pm 21.2$ & $-37.1 \pm 29.4$ & $<0.001$ \\
Simvastatin & $105.5 \pm 50.2$ & $60.6 \pm 20.9$ & $-33.9 \pm 29.9 *$ & $<0.001$ \\
Rosuvastatin & $94.4 \pm 30.6$ & $53.4 \pm 21.4$ & $-40.2 \pm 29.2^{*}$ & $<0.001$ \\
hsCRP (mg/l) & $3.9 \pm 6.9$ & $1.0 \pm 0.8$ & $-20.5 \pm 92.9$ & $<0.001$ \\
Simvastatin (mean) & $2.1 \pm 2.7$ & $1.1 \pm 0.7$ & $11.1 \pm 116.1^{*}$ & 0.096 \\
Simvastatin (median) & $1.2(0.6-2.0)$ & $0.5(0.5-1.8)$ & & $<0.001$ \\
Rosuvastatin (mean) & $5.7 \pm 9.2$ & $0.9 \pm 0.9$ & $-53.5 \pm 41.3^{*}$ & \\
Rosuvastatin (median) & $2.4(1.4-5.0)$ & $0.7(0.4-1.2)$ & & \\
\hline
\end{tabular}

\begin{tabular}{llll}
\hline $\begin{array}{l}\text { Baseline } \\
(\mathrm{n}=51)\end{array}$ & $\begin{array}{l}\text { Follow-up } \\
(\mathrm{n}=51)\end{array}$ & $\begin{array}{l}\text { Percent change } \\
(\%)\end{array}$ & $P$ \\
\hline
\end{tabular}

Analyzed segments (mm)

Total bifurcation length

Distal segment length

Just bifurcation length

Proximal segment length

EEM volume $\left(\mathrm{mm}^{3}\right)$

Lumen volume $\left(\mathrm{mm}^{3}\right)$

P\&M volume $\mathrm{mm}^{3}$

Plaque burden (\%)

Absolute volume $\left(\mathrm{mm}^{3}\right)$

DC

FI

FF

NC

$\begin{aligned} 13.5 & \pm 1.2 \\ 5.0 & \pm 0.1 \\ 2.5 & \pm 0.7 \\ 5.0 & \pm 0.3 \\ 241.0 & \pm 57.0 \\ 125.2 & \pm 31.7 \\ 115.7 & \pm 35.5 \\ 47.7 & \pm 7.0\end{aligned}$

$13.5 \pm 1.1$

$5.0 \pm 0.1$

$2.5 \pm 0.7$

$5.0 \pm 0.3$

\begin{tabular}{|c|c|c|}
\hline $232.4 \pm 54.2$ & $-3.2 \pm 7.3$ & 0.005 \\
\hline $126.3 \pm 31.3$ & $1.3 \pm 8.7$ & 0.476 \\
\hline $106.1 \pm 29.3$ & $-7.0 \pm 11.3$ & $<0.001$ \\
\hline $45.5 \pm 5.7$ & $-4.1 \pm 7.7$ & $<0.001$ \\
\hline $11.0 \pm 8.5$ & $92.5 \pm 143.4$ & $<0.001$ \\
\hline $24.1 \pm 11.7$ & $-28.3 \pm 28.8$ & $<0.001$ \\
\hline $2.3 \pm 2.0$ & $-32.5 \pm 60.7$ & $<0.001$ \\
\hline $19.8 \pm 13.5$ & $29.4 \pm 61.7$ & 0.053 \\
\hline
\end{tabular}

Percentages (\%)

\begin{tabular}{lccrr} 
DC $(\%)$ & $11.0 \pm 6.9$ & $18.8 \pm 10.7$ & $115.1 \pm 155.5$ & $<0.001$ \\
FI (\%) & $55.8 \pm 10.6$ & $44.2 \pm 15.8$ & $-19.8 \pm 27.9$ & $<0.001$ \\
FF (\%) & $8.0 \pm 4.8$ & $4.4 \pm 3.4$ & $-21.9 \pm 75.8$ & $<0.001$ \\
NC $(\%)$ & $25.2 \pm 9.0$ & $32.6 \pm 10.6$ & $45.8 \pm 68.8$ & $<0.001$ \\
\hline
\end{tabular}

patients treated with rosuvastatin, necrotic core progression was halted $\left(14.3 \pm 6.7\right.$ to $15.6 \pm 8.7 \mathrm{~mm}^{3}$, $P=0.423$ ). Also, there were no significant differences of changes in volume for each of the plaque components between the simvastatin and rosuvastatin treatment groups ( $P$ values are not shown) (Table 4$)$. Of note, most patients in the rosuvastatin treatment group $(n=18$, $75 \%$ ) had mean hsCRP levels below the mean of the population and $50 \%$ had mean levels of both LDLcholesterol and hsCRP levels below the mean of the population at 1 year. However, in the simvastatin treatment group, 13 patients $(55 \%)$ had mean hsCRP levels and $38 \%$ had mean levels of both LDL-cholesterol and hsCRP below the mean of the population at 1 year.

Overall, twenty-seven patients had mean value of LDL-cholesterol levels below the mean of the 
Table 4 Comparison of changes in geometric and compositional characteristics at bifurcation sites between the simvastatin and rosuvastatin treatment groups
Values are presented mean $\pm \mathrm{SD}$

EEM external elastic membrane, $P \& M$ plaque and media, $D C$ dense calcium, FI fibrous, FF fibrofatty, $N C$ necrotic core ${ }^{*} P<0.396 ;{ }^{\star} P<0.355$; ${ }^{\S} P<0.567 ;{ }^{\top} P<0.122$
Baseline

Follow-up

Simvastatin $20 \mathrm{mg}(\mathrm{n}=24)$

$\operatorname{EEM}\left(\mathrm{mm}^{3}\right) \quad 255.6 \pm 67.6$

Lumen $\left(\mathrm{mm}^{3}\right)$

$130.2 \pm 38.5$

P\&M $\left(\mathrm{mm}^{3}\right)$

$125.3 \pm 44.0$

Absolute volume $\left(\mathrm{mm}^{3}\right)$

DC $\left(\mathrm{mm}^{3}\right)$

FI $\left(\mathrm{mm}^{3}\right)$

$\mathrm{FF}\left(\mathrm{mm}^{3}\right)$

$\mathrm{NC}\left(\mathrm{mm}^{3}\right)$

$$
\begin{aligned}
7.8 & \pm 5.8 \\
41.1 & \pm 23.6 \\
5.7 & \pm 4.3 \\
19.7 & \pm 13.9
\end{aligned}
$$

\begin{tabular}{|c|c|}
\hline $\mathrm{DC}(\%)$ & $10.6 \pm 5.8$ \\
\hline FI $(\%)$ & $55.5 \pm 10.9$ \\
\hline $\mathrm{FF}(\%)$ & $8.1 \pm 5.2$ \\
\hline $\mathrm{NC}(\%)$ & $25.7 \pm 9.7$ \\
\hline
\end{tabular}

Percentages (\%)

Rosuvastatin $10 \mathrm{mg}(\mathrm{n}=24)$

Vessel $\left(\mathrm{mm}^{3}\right)$
Lumen $\left(\mathrm{mm}^{3}\right)$
Plaque $\left(\mathrm{mm}^{3}\right)$

$226.9 \pm 40.9$

$120.4 \pm 23.1$

Plaque $\left(\mathrm{mm}^{3}\right)$

$106.5 \pm 22.0$

Absolute volume $\left(\mathrm{mm}^{3}\right)$

$\begin{array}{lrl}\mathrm{DC}\left(\mathrm{mm}^{3}\right) & 6.4 & \pm 4.9 \\ \mathrm{FI}\left(\mathrm{mm}^{3}\right) & 33.0 & \pm 13.0 \\ \mathrm{FF}\left(\mathrm{mm}^{3}\right) & 4.6 & \pm 3.3 \\ \mathrm{NC}\left(\mathrm{mm}^{3}\right) & 14.3 \pm 6.7\end{array}$

Percentages (\%)

$\begin{array}{lc}\text { DC }(\%) & 11.4 \pm 7.9 \\ \text { FI }(\%) & 56.2 \pm 10.6 \\ \text { FF }(\%) & 7.8 \pm 4.4 \\ \text { NC }(\%) & 24.6 \pm 8.5\end{array}$

$243.2 \pm 62.1$
$129.7 \pm 37.7$
$113.5 \pm 33.5$

$-4.2 \pm 8.5$

0.026

$-6.7 \pm 13.4$

0.827

$13.6 \pm 10.5$

$110.1 \pm 151.1$

$<0.001$

$23.8 \pm 12.2$

$-32.2 \pm 29.2$

$-37.5 \pm 58.7$

$<0.001$

$2.1 \pm 2.2$

$43.1 \pm 70.5$

0.001

0.029

$20.0 \pm 10.3$

$127.8 \pm 148.5^{*}$

$<0.001$

$40.6 \pm 15.9$

$-26.3 \pm 26.6^{*}$

$<0.001$

$3.9 \pm 3.3$

$-29.3 \pm 70.3^{\S}$

0.001

$35.5 \pm 10.3$

$59.3 \pm 79.4^{\curvearrowleft}$

0.001
$222.0 \pm 44.1$
$23.1 \pm 23.8$

$-2.3 \pm 5.8$

0.087

$2.4 \pm 8.0$

0.168

$98.9 \pm 23.0$

$-7.2 \pm 9.2$

0.001

$8.5 \pm 4.8$
$24.2 \pm 11.4$

$\begin{array}{rlr}75.6 & \pm 136.4 & 0.008 \\ -24.6 & \pm 28.4 & <0.001 \\ -27.6 & \pm 63.3 & 0.001 \\ 16.3 & \pm 49.9 & 0.423\end{array}$

$2.4 \pm 1.8$

$102.9 \pm 163.9 *$

$<0.001$

$17.7 \pm 11.1$

$-13.7 \pm 28.3^{\ddagger}$

0.006

$4.8+3.5$

$-14.7 \pm 81.6^{\S}$

0.006

$29.8 \pm 10.4$

$32.9 \pm 55.2$

0.036 population, and among them, 9 patients had a decrease in necrotic core volume 1 year later ( 3 patients were treated with simvastatin and 6 patients were treated with rosuvastatin). In addition, 31 patients had mean hsCRP levels below the mean of the population and among them, 8 patients had a decrease in necrotic core volume. All of them were rosuvastatin-treated patients (Fig. 2).

Serial changes in geometric and compositional variables in bifurcation subsegments

Subsegmental analyses in bifurcation lesions are shown in Table 5. EEM, Plaque area and plaque burden decreased after 1 year in all bifurcation subsegments. At baseline and follow-up, dense calcium and necrotic core areas including percentages of proximal subsegments were significantly greater than those of distal bifurcation subsegments. Of interest, in all bifurcation subsegments, dense calcium area increased after 1 year $\left(0.66 \pm 0.53\right.$ vs. $1.00 \pm 0.77 \mathrm{~mm}^{2}$ in proximal; $0.51 \pm 0.44$ vs. $0.81 \pm 0.71 \mathrm{~mm}^{2}$ in bifurcation only; and $0.39 \pm 0.39$ vs. $0.63 \pm 0.65 \mathrm{~mm}^{2}$ in distal subsegments). Fibrous and fibrofatty areas decreased after 1 year in all subsegments. Necrotic core area remained unchanged but relative content (percentage) increased in all 3 subsegments (Table 5).

Independent clinical predictors for decrease in necrotic core volume

All baseline, demographic and laboratory measurements were tested in univariate analysis for their correlation with a decrease in necrotic core volume. All variables that had a $P<0.2$ value were entered 


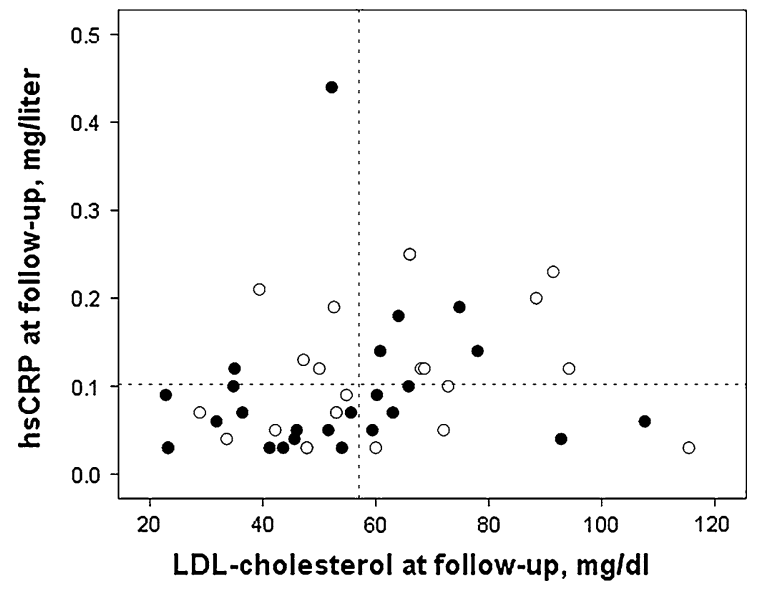

Fig. 2 End of study LDL-cholesterol and hsCRP values. Dotted lines indicate the mean values for the population in this study. Fifty percent of the rosuvastatin treatment group is below the mean LDL cholesterol and hsCRP levels at follow-up (white circle $=$ simvastatin treatment group, black circle $=$ rosuvastatin treatment group)

into the multiple logistic regression model; variables included gender, age, types of statin, clinical status, percent change of plaque volume, percent change of HDL-cholesterol level and percent change of hsCRP level. Ultimately, the two independent clinical predictors for decrease in necrotic core volume were the percent change of HDL-cholesterol level $(P=0.041$, odds ratio: $1.052,95 \%$ confidence interval $(\mathrm{CI}): 1.002$ to 1.104) and percent change of hsCRP level $(P=0.021$, odds ratio: $0.989,95 \%$ CI: 0.980 to $0.998)$.

\section{Discussion}

The present study shows for the first time serial changes in geometric and compositional characteristics of coronary atherosclerotic plaques at bifurcation sites by intravascular ultrasound virtual histology in patients treated with statins. The main findings of this study are: (1) Overall plaque volume at bifurcations significantly decreased following 1 year of statin treatment. (2) Overall mean dense calcium and necrotic core areas of proximal subsegments were larger than those of distal bifurcation subsegments. (3) At 1 year, overall and in each bifurcation subsegment, dense calcium volume significantly increased, while fibrous and fibrofatty volumes significantly decreased, and necrotic core volume did not change significantly.
(4) At 1 year, there were no significant differences in plaque component volumes between the simvastatin and rosuvastatin treatment groups. However, within groups, necrotic core volume significantly increased in the simvastatin treatment group, while there was no increase in necrotic core volume in the rosuvastatin treatment group. (5) The independent predictors by multiple stepwise logistic regression analysis of decrease in necrotic core volume were the percent change of HDL-cholesterol level and the percent change of hsCRP level.

Many clinical trials have shown that statins can significantly reduce the incidence of cardiovascular events in both primary and secondary prevention [16, 17]. Although imaging studies of coronary plaques have contributed considerably to our understanding of the benefits of lipid-lowering therapies, effect of statin treatment on bifurcation coronary plaques using $\mathrm{VH}$ IVUS has not been sufficiently evaluated. In addition, the effect of statins on plaque size cannot be seen as a class effect, because the results of various studies have shown different effect. For example, in the REVERSAL [9] study, moderate lipid-lowering therapy with $40 \mathrm{mg}$ of pravastatin did not halt plaque progression, while treatment with $80 \mathrm{mg}$ of atorvastatin did. The first study showing reduction on plaque size was the ASTEROID trial using $40 \mathrm{mg}$ of rosuvastatin [8]. However, these trials have only evaluated quantitative changes of coronary artery plaque using gray-scale IVUS but did not study plaque composition change. Although several recent papers showed various results on serial changes of plaque composition with various statin treatments, none of them focused on bifurcation lesions.

In a previous study, patients with stable angina pectoris $(\mathrm{n}=80)$ treated with fluvastatin for 1 year had significant regression of plaque volume, and changes in atherosclerotic plaque composition with a significant reduction of fibrofatty volume $(P<0.0001)$. This change in fibrofatty volume had a significant correlation with change in LDL-cholesterol level $(r=0.703$, $P<0.0001)$ and change in hsCRP level $(r=0.357$, $P=0.006)$ [18]. Of note, the necrotic core did not change significantly. In a randomized study by Hong et al., that included 100 patients with stable angina and ACS treated with rosuvastatin $10 \mathrm{mg}$ and simvastatin $20 \mathrm{mg}$ for 1 year, overall necrotic core volume significantly decreased $(P=0.010)$ and fibrofatty plaque volume increased $(P=0.006)$ after statin treatments. Particularly, there was a significant decrease in necrotic 
Table 5 Changes of geometric and compositional characteristics for each bifurcation subsegment

\section{Baseline $(\mathrm{n}=51) \quad$ Follow-up $(\mathrm{n}=51) \quad$ Percent change $(\%) \quad P$}

\section{Geometric parameters}

Proximal

\section{Compositional parameters}

Proximal

\begin{tabular}{|c|c|c|c|c|c|}
\hline & $\operatorname{EEM}\left(\mathrm{mm}^{2}\right)$ & $19.0 \pm 4.1$ & $18.3 \pm 4.0$ & $-3.8 \pm 4.6$ & $<0.001$ \\
\hline & Lumen $\left(\mathrm{mm}^{2}\right)$ & $9.4 \pm 2.6$ & $9.5 \pm 2.5$ & $2.4 \pm 11.2$ & 0.924 \\
\hline & $\mathrm{P} \& \mathrm{M}\left(\mathrm{mm}^{2}\right)$ & $9.6 \pm 2.7$ & $8.7 \pm 2.2$ & $-7.9 \pm 10.0$ & $<0.001$ \\
\hline & Plaque burden $(\%)$ & $50.4 \pm 8.7$ & $47.9 \pm 6.8$ & $-4.2 \pm 8.7$ & $<0.001$ \\
\hline & \multicolumn{5}{|l|}{ Bifurcation only } \\
\hline & $\operatorname{EEM}\left(\mathrm{mm}^{2}\right)$ & $18.1 \pm 4.0$ & $17.4 \pm 3.9$ & $-3.7 \pm 6.6$ & $<0.001$ \\
\hline & Lumen $\left(\mathrm{mm}^{2}\right)$ & $9.8 \pm 2.5$ & $9.7 \pm 2.4$ & $-0.3 \pm 9.3$ & 0.862 \\
\hline & $\mathrm{P} \& \mathrm{M}\left(\mathrm{mm}^{2}\right)$ & $8.3 \pm 2.9$ & $7.7 \pm 2.3$ & $-5.3 \pm 14.5$ & 0.002 \\
\hline & Plaque burden $(\%)$ & $45.2 \pm 9.8$ & $43.9 \pm 8.1$ & $-1.9 \pm 11.5$ & 0.042 \\
\hline & \multicolumn{5}{|l|}{ Distal } \\
\hline & $\operatorname{EEM}\left(\mathrm{mm}^{2}\right)$ & $16.5 \pm 3.9$ & $16.0 \pm 3.9$ & $-2.9 \pm 5.5$ & $<0.001$ \\
\hline & Lumen $\left(\mathrm{mm}^{2}\right)$ & $8.8 \pm 2.2$ & $8.8 \pm 2.2$ & $0.8 \pm 8.0$ & 0.847 \\
\hline & $\mathrm{P} \& \mathrm{M}\left(\mathrm{mm}^{2}\right)$ & $7.7 \pm 2.8$ & $7.1 \pm 2.5$ & $-6.0 \pm 11.8$ & 0.001 \\
\hline & Plaque burden $(\%)$ & $45.9 \pm 8.8$ & $44.0 \pm 8.1$ & $-3.4 \pm 8.9$ & 0.004 \\
\hline & \multicolumn{5}{|c|}{ Compositional parameters } \\
\hline & \multicolumn{5}{|l|}{ Proximal } \\
\hline & $\mathrm{DC}\left(\mathrm{mm}^{2}\right)$ & $0.66 \pm 0.53$ & $1.00 \pm 0.77$ & $137.1 \pm 270.4$ & $<0.001$ \\
\hline & $\mathrm{DC}(\%)$ & $11.6 \pm 8.1$ & $19.2 \pm 11.9$ & $174.4 \pm 353.9$ & $<0.001$ \\
\hline & $\mathrm{FI}\left(\mathrm{mm}^{2}\right)$ & $3.14 \pm 1.60$ & $2.04 \pm 1.03$ & $-24.0 \pm 43.1$ & $<0.001$ \\
\hline & FI $(\%)$ & $55.0 \pm 12.6$ & $43.5 \pm 17.0$ & $-19.0 \pm 32.3$ & $<0.001$ \\
\hline & $\mathrm{FF}\left(\mathrm{mm}^{2}\right)$ & $0.39 \pm 0.29$ & $0.19 \pm 0.19$ & $-22.8 \pm 74.7$ & $<0.001$ \\
\hline & $\mathrm{FF}(\%)$ & $7.2 \pm 4.8$ & $4.1 \pm 3.5$ & $-12.9 \pm 95.9$ & $<0.001$ \\
\hline & $\mathrm{NC}\left(\mathrm{mm}^{2}\right)$ & $1.55 \pm 0.90$ & $1.74 \pm 1.07$ & $30.1 \pm 65.7$ & 0.072 \\
\hline & $\mathrm{NC}(\%)$ & $26.2 \pm 9.7$ & $33.2 \pm 11.2$ & $45.8 \pm 82.2$ & 0.001 \\
\hline & \multicolumn{5}{|l|}{ Bifurcation only } \\
\hline & $\mathrm{DC}\left(\mathrm{mm}^{2}\right)$ & $0.51 \pm 0.44$ & $0.81 \pm 0.71$ & $145.0 \pm 247.0$ & $<0.001$ \\
\hline & $\mathrm{DC}(\%)$ & $10.9 \pm 8.6$ & $19.0 \pm 12.3$ & $223.1 \pm 381.5$ & $<0.001$ \\
\hline & $\mathrm{FI}\left(\mathrm{mm}^{2}\right)$ & $2.67 \pm 1.51$ & $1.81 \pm 1.04$ & $-26.0 \pm 34.3$ & $<0.001$ \\
\hline & FI $(\%)$ & $56.3 \pm 12.6$ & $45.9 \pm 17.7$ & $-18.5 \pm 27.7$ & $<0.001$ \\
\hline & $\mathrm{FF}\left(\mathrm{mm}^{2}\right)$ & $0.42 \pm 0.32$ & $0.19 \pm 0.18$ & $-27.2 \pm 75.1$ & $<0.001$ \\
\hline & $\mathrm{FF}(\%)$ & $9.4 \pm 6.3$ & $5.1 \pm 3.9$ & $-12.9 \pm 100.6$ & $<0.001$ \\
\hline & $\mathrm{NC}\left(\mathrm{mm}^{2}\right)$ & $1.21 \pm 1.00$ & $1.39 \pm 1.08$ & $42.6 \pm 93.0$ & 0.208 \\
\hline & $\mathrm{NC}(\%)$ & $23.4 \pm 10.8$ & $29.9 \pm 11.8$ & $56.5 \pm 96.3$ & 0.001 \\
\hline & \multicolumn{5}{|l|}{ Distal } \\
\hline & $\mathrm{DC}\left(\mathrm{mm}^{2}\right)$ & $0.39 \pm 0.39$ & $0.63 \pm 0.65$ & $133.3 \pm 363.8$ & $<0.001$ \\
\hline & $\mathrm{DC}(\%)$ & $9.7 \pm 7.4$ & $16.9 \pm 11.0$ & $152.3 \pm 301.3$ & $<0.001$ \\
\hline & $\mathrm{FI}\left(\mathrm{mm}^{2}\right)$ & $2.36 \pm 1.44$ & $1.61 \pm 1.06$ & $-26.4 \pm 32.6$ & $<0.001$ \\
\hline $\begin{array}{l}\text { Values are presented } \\
\text { mean } \pm \text { SD }\end{array}$ & FI $(\%)$ & $58.7 \pm 11.4$ & $47.4 \pm 17.2$ & $-18.0 \pm 29.5$ & $<0.001$ \\
\hline$E E M$ external elastic & $\mathrm{FF}\left(\mathrm{mm}^{2}\right)$ & $0.35 \pm 0.30$ & $0.15 \pm 0.14$ & $-36.7 \pm 57.3$ & $<0.001$ \\
\hline membrane, $P \& M$ plaque and & $\mathrm{FF}(\%)$ & $9.1 \pm 5.6$ & $5.0 \pm 4.8$ & $-24.3 \pm 79.9$ & $<0.001$ \\
\hline media, $D C$ dense calcium, $F I$ & $\mathrm{NC}\left(\mathrm{mm}^{2}\right)$ & $1.00 \pm 0.94$ & $1.24 \pm 1.07$ & $46.8 \pm 95.4$ & 0.021 \\
\hline $\begin{array}{l}\text { fibrous, } F F \text { fibrofatty, } N C \\
\text { necrotic core }\end{array}$ & $\mathrm{NC}(\%)$ & $22.5 \pm 10.3$ & $30.7 \pm 12.4$ & $61.3 \pm 97.1$ & $<0.001$ \\
\hline
\end{tabular}

\begin{tabular}{|c|c|c|c|c|c|}
\hline & $\operatorname{EEM}\left(\mathrm{mm}^{2}\right)$ & $19.0 \pm 4.1$ & $18.3 \pm 4.0$ & $-3.8 \pm 4.6$ & $<0.001$ \\
\hline & Lumen $\left(\mathrm{mm}^{2}\right)$ & $9.4 \pm 2.6$ & $9.5 \pm 2.5$ & $2.4 \pm 11.2$ & 0.924 \\
\hline & $\mathrm{P} \& \mathrm{M}\left(\mathrm{mm}^{2}\right)$ & $9.6 \pm 2.7$ & $8.7 \pm 2.2$ & $-7.9 \pm 10.0$ & $<0.001$ \\
\hline & Plaque burden $(\%)$ & $50.4 \pm 8.7$ & $47.9 \pm 6.8$ & $-4.2 \pm 8.7$ & $<0.001$ \\
\hline & \multicolumn{5}{|l|}{ Bifurcation only } \\
\hline & $\operatorname{EEM}\left(\mathrm{mm}^{2}\right)$ & $18.1 \pm 4.0$ & $17.4 \pm 3.9$ & $-3.7 \pm 6.6$ & $<0.001$ \\
\hline & Lumen $\left(\mathrm{mm}^{2}\right)$ & $9.8 \pm 2.5$ & $9.7 \pm 2.4$ & $-0.3 \pm 9.3$ & 0.862 \\
\hline & $\mathrm{P} \& \mathrm{M}\left(\mathrm{mm}^{2}\right)$ & $8.3 \pm 2.9$ & $7.7 \pm 2.3$ & $-5.3 \pm 14.5$ & 0.002 \\
\hline & Plaque burden $(\%)$ & $45.2 \pm 9.8$ & $43.9 \pm 8.1$ & $-1.9 \pm 11.5$ & 0.042 \\
\hline & \multicolumn{5}{|l|}{ Distal } \\
\hline & $\operatorname{EEM}\left(\mathrm{mm}^{2}\right)$ & $16.5 \pm 3.9$ & $16.0 \pm 3.9$ & $-2.9 \pm 5.5$ & $<0.001$ \\
\hline & Lumen $\left(\mathrm{mm}^{2}\right)$ & $8.8 \pm 2.2$ & $8.8 \pm 2.2$ & $0.8 \pm 8.0$ & 0.847 \\
\hline & $\mathrm{P} \& \mathrm{M}\left(\mathrm{mm}^{2}\right)$ & $7.7 \pm 2.8$ & $7.1 \pm 2.5$ & $-6.0 \pm 11.8$ & 0.001 \\
\hline & Plaque burden $(\%)$ & $45.9 \pm 8.8$ & $44.0 \pm 8.1$ & $-3.4 \pm 8.9$ & 0.004 \\
\hline & \multicolumn{5}{|c|}{ Compositional parameters } \\
\hline & \multicolumn{5}{|l|}{ Proximal } \\
\hline & $\mathrm{DC}\left(\mathrm{mm}^{2}\right)$ & $0.66 \pm 0.53$ & $1.00 \pm 0.77$ & $137.1 \pm 270.4$ & $<0.001$ \\
\hline & $\mathrm{DC}(\%)$ & $11.6 \pm 8.1$ & $19.2 \pm 11.9$ & $174.4 \pm 353.9$ & $<0.001$ \\
\hline & $\mathrm{FI}\left(\mathrm{mm}^{2}\right)$ & $3.14 \pm 1.60$ & $2.04 \pm 1.03$ & $-24.0 \pm 43.1$ & $<0.001$ \\
\hline & FI $(\%)$ & $55.0 \pm 12.6$ & $43.5 \pm 17.0$ & $-19.0 \pm 32.3$ & $<0.001$ \\
\hline & $\mathrm{FF}\left(\mathrm{mm}^{2}\right)$ & $0.39 \pm 0.29$ & $0.19 \pm 0.19$ & $-22.8 \pm 74.7$ & $<0.001$ \\
\hline & $\mathrm{FF}(\%)$ & $7.2 \pm 4.8$ & $4.1 \pm 3.5$ & $-12.9 \pm 95.9$ & $<0.001$ \\
\hline & $\mathrm{NC}\left(\mathrm{mm}^{2}\right)$ & $1.55 \pm 0.90$ & $1.74 \pm 1.07$ & $30.1 \pm 65.7$ & 0.072 \\
\hline & $\mathrm{NC}(\%)$ & $26.2 \pm 9.7$ & $33.2 \pm 11.2$ & $45.8 \pm 82.2$ & 0.001 \\
\hline & \multicolumn{5}{|l|}{ Bifurcation only } \\
\hline & $\mathrm{DC}\left(\mathrm{mm}^{2}\right)$ & $0.51 \pm 0.44$ & $0.81 \pm 0.71$ & $145.0 \pm 247.0$ & $<0.001$ \\
\hline & $\mathrm{DC}(\%)$ & $10.9 \pm 8.6$ & $19.0 \pm 12.3$ & $223.1 \pm 381.5$ & $<0.001$ \\
\hline & $\mathrm{FI}\left(\mathrm{mm}^{2}\right)$ & $2.67 \pm 1.51$ & $1.81 \pm 1.04$ & $-26.0 \pm 34.3$ & $<0.001$ \\
\hline & FI $(\%)$ & $56.3 \pm 12.6$ & $45.9 \pm 17.7$ & $-18.5 \pm 27.7$ & $<0.001$ \\
\hline & $\mathrm{FF}\left(\mathrm{mm}^{2}\right)$ & $0.42 \pm 0.32$ & $0.19 \pm 0.18$ & $-27.2 \pm 75.1$ & $<0.001$ \\
\hline & $\mathrm{FF}(\%)$ & $9.4 \pm 6.3$ & $5.1 \pm 3.9$ & $-12.9 \pm 100.6$ & $<0.001$ \\
\hline & $\mathrm{NC}\left(\mathrm{mm}^{2}\right)$ & $1.21 \pm 1.00$ & $1.39 \pm 1.08$ & $42.6 \pm 93.0$ & 0.208 \\
\hline & $\mathrm{NC}(\%)$ & $23.4 \pm 10.8$ & $29.9 \pm 11.8$ & $56.5 \pm 96.3$ & 0.001 \\
\hline & \multicolumn{5}{|l|}{ Distal } \\
\hline & $\mathrm{DC}\left(\mathrm{mm}^{2}\right)$ & $0.39 \pm 0.39$ & $0.63 \pm 0.65$ & $133.3 \pm 363.8$ & $<0.001$ \\
\hline & $\mathrm{DC}(\%)$ & $9.7 \pm 7.4$ & $16.9 \pm 11.0$ & $152.3 \pm 301.3$ & $<0.001$ \\
\hline & $\mathrm{FI}\left(\mathrm{mm}^{2}\right)$ & $2.36 \pm 1.44$ & $1.61 \pm 1.06$ & $-26.4 \pm 32.6$ & $<0.001$ \\
\hline $\begin{array}{l}\text { Values are presented } \\
\text { mean } \pm \text { SD }\end{array}$ & FI $(\%)$ & $58.7 \pm 11.4$ & $47.4 \pm 17.2$ & $-18.0 \pm 29.5$ & $<0.001$ \\
\hline$E E M$ external elastic & $\mathrm{FF}\left(\mathrm{mm}^{2}\right)$ & $0.35 \pm 0.30$ & $0.15 \pm 0.14$ & $-36.7 \pm 57.3$ & $<0.001$ \\
\hline membrane, $P \& M$ plaque and & $\mathrm{FF}(\%)$ & $9.1 \pm 5.6$ & $5.0 \pm 4.8$ & $-24.3 \pm 79.9$ & $<0.001$ \\
\hline media, $D C$ dense calcium, $F I$ & $\mathrm{NC}\left(\mathrm{mm}^{2}\right)$ & $1.00 \pm 0.94$ & $1.24 \pm 1.07$ & $46.8 \pm 95.4$ & 0.021 \\
\hline $\begin{array}{l}\text { fibrous, } F F \text { fibrofatty, } N C \\
\text { necrotic core }\end{array}$ & $\mathrm{NC}(\%)$ & $22.5 \pm 10.3$ & $30.7 \pm 12.4$ & $61.3 \pm 97.1$ & $<0.001$ \\
\hline
\end{tabular}

Values are presented mean $\pm \mathrm{SD}$

EEM external elastic membrane, $P \& M$ plaque and media, $D C$ dense calcium, $F I$ fibrous, $F F$ fibrofatty, $N C$ necrotic core 
core volume $(P=0.015)$ in the rosuvastatin-treated subgroup. However, in our study only including bifurcation lesions, necrotic core content did not decrease and dense calcium content significantly increased in rosuvastatin-treated patients. It is not clear whether these are lesion-specific findings. Also at variance with our study, by multiple stepwise logistic regression analysis, they showed that the only independent clinical predictor of decrease in necrotic core volume was baseline HDL-cholesterol level $(P=0.040$, odds ratio: $1.044,95 \%$ confidence interval (CI): 1.002 to 1.089 ) [19]. In our study, we found that the independent clinical predictors by multiple stepwise logistic regression analysis of decrease in necrotic core volume were the percent change (i.e. instead of baseline value as in the study by Hong et al.) of HDL-cholesterol level $(P=0.041$, odds ratio: $1.052,95 \%$ confidence interval (CI): 1.002 to 1.104) and percent change of hsCRP level $(P=0.021$, odds ratio: $0.989,95 \%$ CI: 0.980 to 0.998$)$.

It has been suggested that the efficacy of statin therapy is partly due to the "anti-inflammatory" properties of these agents, that is they have also a marked LDL cholesterol-independent effect [20]. In the JUPITER trial, 17802 subjects with no history of cardiovascular disease, low LDL cholesterol level $(<130 \mathrm{mg} / \mathrm{dl})$, and a high plasma level of C-reactive protein (CRP $\geq 2 \mathrm{mg} / \mathrm{dl}$ ), were randomized to rosuvastatin $20 \mathrm{mg}$ or placebo daily. There was a $46 \%$ reduction in cardiovascular events for patients randomized to rosuvastatin $(P<0.0001)$. Thus, the JUPITER trial substantiates that the benefits of statins relate in part to decreased inflammation. In our study, there was a significant change in hsCRP level only in the rosuvastatin treatment group. Indeed patients who achieved hsCRP values below the mean of the population and presented a decrease in NC were treated with rosuvastatin. Due to the nature of the present study (i.e. retrospective), in the group of patients receiving rosuvastatin, the baseline hsCRP values were somehow higher as compared to those in the simvastatin group.

It has been reported in another manuscript which plaque burden and necrotic core are larger in bifurcation lesions compared to non-bifurcation lesions [21]. Thus, it is expected that a greater change would occur in bifurcation lesions. To our knowledge this is the first report looking specifically into changes within bifurcation lesions.

\section{Limitations}

This study has several limitations. (1) It is a retrospective and single-center study. (2) It includes a relatively small population to show serial changes in plaque composition. To avoid type II error, a prospective, double blinded, large study is needed to compare the changes in plaque composition between statin treatment groups. The ongoing IBIS 3 study, not only evaluates the serial compositional changes in a long coronary segment $(>40 \mathrm{~mm})$ in patients receiving $40 \mathrm{mg}$ rosuvastatin but it will also specifically assesses serial compositional changes in bifurcation lesions.

The current report did not include the assessment of bifurcation angle (BA), we rather looked into the serial changes in plaque size and composition within bifurcation lesions. It is known that the BA can influence the presence and phenotype of atherosclerotic plaque in the proximal bifurcation segment. Data from computational fluid dynamics and histopathology studies have confirmed this finding by demonstrating that the hemodynamic phenomena, which are important in atherogenesis, are more pronounced in the large angle bifurcation.

\section{Conclusions}

After 1 year, overall dense calcium volume significantly increased whilst fibrous and fibrofatty volumes significantly decreased and no significant change in the content of necrotic core was observed in bifurcation lesion. The changes in the volumes of all plaque components were not statistically different between the simvastatin and rosuvastatin treatment groups; however, halting of necrotic core progression was apparent in the rosuvastatin group.

Conflict of interest None.

\section{References}

1. Katritsis DG, Pantos I, Korovesis S et al (2009) Threedimensional analysis of vulnerable segments in the left anterior descending artery. Coron Artery Dis 20:199-206

2. Thomas JB, Antiga L, Che SL et al (2005) Variation in the carotid bifurcation geometry of young versus older adults: implications for geometric risk of atherosclerosis. Stroke 36:2450-2456 
3. Gonzalo N, Garcia-Garcia HM, Regar E et al (2009) In vivo assessment of high-risk coronary plaques at bifurcations with combined intravascular ultrasound and optical coherence tomography. JACC Cardiovasc Imaging 2:473-482

4. Al Suwaidi J, Berger PB, Rihal CS et al (2000) Immediate and long-term outcome of intracoronary stent implantation for true bifurcation lesions. J Am Coll Cardiol 35:929-936

5. Colombo A, Moses JW, Morice MC et al (2004) Randomized study to evaluate sirolimus-eluting stents implanted at coronary bifurcation lesions. Circulation 109: 1244-1249

6. Ge L, Airoldi F, Iakovou I et al (2005) Clinical and angiographic outcome after implantation of drug-eluting stents in bifurcation lesions with the crush stent technique: Importance of final kissing balloon post-dilation. J Am Coll Cardiol 46:613-620

7. MRC/BHF Heart protection study of cholesterol lowering with simvastatin in 20[punctuation space]536 high-risk individuals: a randomised placebocontrolled trial. The Lancet 2002;360:7-22

8. Nissen SE, Nicholls SJ, Sipahi I et al (2006) Effect of very high-intensity statin therapy on regression of coronary atherosclerosis: the ASTEROID trial. JAMA 295:1556-1565

9. Nissen SE, Tuzcu EM, Schoenhagen P et al (2004) Effect of intensive compared with moderate lipid-lowering therapy on progression of coronary atherosclerosis: a randomized controlled trial. JAMA 291:1071-1080

10. Garcia-Garcia HM, Gonzalo N, Regar E et al (2009) Virtual histology and optical coherence tomography: from research to a broad clinical application. Heart 95:1362-1374

11. Valgimigli M, Rodriguez-Granillo GA, Garcia-Garcia HM et al (2006) Distance from the ostium as an independent determinant of coronary plaque composition in vivo: an intravascular ultrasound study based radiofrequency data analysis in humans. Eur Heart J 27:655-663

12. Rodriguez-Granillo GA, Garcia-Garcia HM, Valgimigli M et al (2006) Global characterization of coronary plaque rupture phenotype using three-vessel intravascular ultrasound radiofrequency data analysis. Eur Heart J 27: 1921-1927

13. Nasu K, Tsuchikane E, Katoh O et al (2006) Accuracy of in vivo coronary plaque morphology assessment: a validation study of in vivo virtual histology compared with in vitro histopathology. J Am Coll Cardiol 47:2405-2412

14. Mintz GS, Nissen SE, Anderson WD et al (2001) American college of cardiology clinical expert consensus document on standards for acquisition, measurement and reporting of intravascular ultrasound studies (ivus): a report of the american college of cardiology task force on clinical expert consensus documents developed in collaboration with the european society of cardiology endorsed by the society of cardiac angiography and interventions. J Am Coll Cardiol 37:1478-1492

15. Nair A, Kuban BD, Tuzcu EM et al (2002) Coronary plaque classification with intravascular ultrasound radiofrequency data analysis. Circulation 106:2200-2206

16. Shepherd J, Cobbe SM, Ford I et al (1995) Prevention of coronary heart disease with pravastatin in men with hypercholesterolemia. N Engl J Med 333:1301-1308

17. The long-term intervention with pravastatin in ischaemic disease study group. Prevention of cardiovascular events and death with pravastatin in patients with coronary heart disease and a broad range of initial cholesterol levels. N Engl J Med 1998; 339:1349-1357

18. Nasu K, Tsuchikane E, Katoh O et al (2009) Effect of fluvastatin on progression of coronary atherosclerotic plaque evaluated by virtual histology intravascular ultrasound. JACC Cardiovasc Interv 2:689-696

19. Hong MK, Park DW, Lee CW et al (2009) Effects of statin treatments on coronary plaques assessed by volumetric virtual histology intravascular ultrasound analysis. JACC Cardiovasc Interv 2:679-688

20. Ridker PM, Cannon CP, Morrow D et al (2005) C-reactive protein levels and outcomes after statin therapy. N Engl J Med 352:20-28

21. Garcia-Garcia HM, Gomez-Lara J, Gonzalo N et al (2010) A comparison of the distribution of necrotic core in bifurcation and non-bifurcation coronary lesions: an in vivo assessment using intravascular ultrasound radiofrequency data analysis. Eurointervention 6:321-327 